\title{
TITLE: CONSERVATIVE MANAGEMENT OF ACUTE PERFORATED DIVERTICULITIS: A SYSTEMATIC REVIEW
}

\section{SHORT RUNNING TITLE: Management of Perforated Diverticulitis}

AUTHORS: Terence C. Chua BScMed (Hons) MBBS PhD MRCS (Ed) FRACS ${ }^{1,2}$, Arunan Jeyakumar BMedSci², Julian C.Y. Ip MBBS PhD FRACS ${ }^{3,4}$, Peter J. Yuide MBBS FRACS ${ }^{1}$, Matthew J. Burstow MBBS FRACS ${ }^{1}$.

\section{AFFILIATIONS:}

1. Department of Surgery, Logan Hospital, Metro South Health, Meadowbrook, Queensland, Australia.

2. School of Medicine, Griffith University, Gold Coast, Queensland, Australia.

3. Northern Beaches Colorectal, Northern Beaches Hospital, Frenchs Forest, New South Wales, Australia.

4. Faculty of Medicine and Health, The University of Sydney, Camperdown, NSW, Australia.

Corresponding Author: A/Prof Terence Chua; Department of Surgery, Logan Hospital, Metro South Health, Meadowbrook; School of Medicine, Griffith University, Gold Coast, Queensland, Australia. Email: terence.c.chua@gmail.com

Disclosures: Nothing to declare

This article has been accepted for publication and undergone full peer review but has not been through the copyediting, typesetting, pagination and proofreading process which may lead to differences between this version and the Version of Record. Please cite this article as doi: $10.1111 / 1751-2980.12838$ 


\section{ABSTRACT}

\section{Objective}

Acute perforated diverticulitis is frequently observed and spans a spectrum in the severity of its presentation. Emergency surgery is required in patients with generalized peritonitis, however, a large proportion of patients are clinically stable with localized peritonitis. This review aims to examine this specific group of patients by reviewing their outcomes of conservative management.

\section{Methods}

A systematic literature search was performed on the MEDLINE and PubMed databases. The management outcomes of patients undergoing non-operative treatment for acute perforated diverticulitis were synthesized and tabulated.

\section{Results}

Of 479 patients, 412 patients (86\%) were successfully managed non-operatively. Sixty-five patients (13.6\%) failed non-operative treatment and underwent operative surgical management, and two patients died (0.4\%). Emergency surgery includes a Hartmann operation (51\%), resection with anastomosis with or without stoma (27\%), laparoscopic lavage (18\%) and surgical drainage (4\%). The success rate of conservative management was $92.4 \%$ and $71.4 \%$ for patients with pericolic and distant free air respectively. Treatment failure was associated with a high volume of free air, distant free air and presence of an abscess.

\section{Conclusions}


Conservative management is safe and successful in patients with acute perforated diverticulitis without generalized peritonitis. Early recognition of patients who demonstrate clinical signs of persistent perforation is important to ensure the success of this strategy.

\section{INTRODUCTION}

Diverticular disease is common in western society [1]. Although this condition is associated with senescence, epidemiological data suggest an increasing incidence observed in the younger age group [2]. Hospital presentations for symptomatic diverticular disease and its complications of diverticulitis and diverticular bleeding are frequent and translate to a significant economic burden [3]. Majority of diverticulitis are uncomplicated and randomized trials of conservative management that omit antibiotics suggests that this is safe practice and has not been proven to result in delayed complications or recurrent episodes $[4,5]$.

The Hinchey system was described as a classification system for patients with complicated diverticulitis that had perforated [6]. These patients were classified based on the consequence of their perforation and its sequelae. It is determined from computed tomography imaging (Hinchey I and II) or operative findings (Hinchey III and IV). Considerable efforts have been undertaken to investigate the optimal surgical strategy in the group of patients with Hinchey III/IV diverticulitis who need urgent surgery [7]. Hartmann operation was previously regarded the gold standard option, however, the surgical boundaries have been tested with recent randomized trials suggesting that primary anastomosis with a diverting stoma results in a lower permanent stoma rate compared to a Hartmann operation [8]. Nevertheless, a large 
proportion of patients with perforated diverticulitis do not require emergency surgery. These patients are thought to have a contained or sealed perforation that may be associated with an abscess. These commonly encountered subpopulations of perforated diverticulitis patients do not fit within Hinchey's classification, and there is little knowledge of their disease trajectory and predictors of treatment failure from conservative management.

The primary aims of the review are to compile and report the outcomes of patients with perforated diverticulitis who do not require emergency surgery and are suitable for conservative management and the secondary aims are to identify predictors for failure of conservative management. 


\section{METHODS}

\section{Search Strategy}

Original research articles published on diverticulitis with perforation were identified by searching the MEDLINE database (January 2000 to November 2018) and PubMed (January 2000 to November 2018) using the keywords; "diverticulitis, perforation, air". The search was limited to human articles and articles published in the English language. The reference lists of all retrieved articles were manually reviewed to identify amy further relevant studies. All relevant articles identified were assessed with the application of a predetermined selection criterion.

\section{Selection Criteria}

The key selection critieria was to identify studies that specifically reported the clinical outcomes of patients with perforated diverticulitis who were managed conservatively with intravenous antibiotics with or without interventional drainage procedures were evaluated. Perforated diverticulitis was defined as patients with free gas confirmed on computed tomography imaging. Localised perforation is defined as paracolic free gas. Studies which focused on reporting outcomes of emergency surgery or did not adequately describe the disease characteristic of the patient cohort were excluded. To ensure that the sample size would not bias the reporting, only studies reporting more than 10 patients were included. For institutions reporting updated clinical series, only the most recent or complete paper was selected for review. 


\section{Data Extraction and Critical Appraisal}

Two reviewers (T.C.C. and A.J.) independently appraised each article using a standard protocol. Data extracted include the methodology, quality criteria, conservative treatment protocol, use of interventional drainage procedures as an adjunct to medical treatment, medical treatment success rate and predictors of treatment failure. All data were extracted and tabulated from the relevant articles' texts, tables, and figures. Discrepancies were resolved by discussion and consensus. Following the tabulation of the results, the outcomes were synthesized and reported by a narrative review.

\section{Data Analysis}

The data collected according to the predetermined variables as described above was examined. Given the unique topic and the rarity of publications addressing this subject matter, the data collected from single-arm studies without a comparator group. This precludes formal data analysis by forrest plots and a full tabulation of available data was performed. 


\section{RESULTS}

\section{Literature Search}

One thousand eight hundred and thirty-four articles were identified using the above keywords. A language restriction to English and the addition of a study period restriction from January 2000 to November 2018 was applied resulting in exclusion of nine hundred and eighty-seven articles. Full-text articles were assessed for eligibility and eight hundred and thirty-two articles comprising of case reports, review articles, studies focusing on radiological modalities and studies that did not discuss colonic diverticulitis, extra-luminal air, or only diverticular abscess were excluded. After excluding six studies that did not fulfill the primary endpoint, two studies that were repeat publications and three studies with insufficient data to meet the endpoint; six studies were included for review [9-14]. All six studies were retrospective studies evaluating the efficacy of nonoperative management of perforated diverticulitis. All studies included patients with a diagnosis that was CT confirmed, accounting for 479 patients (Figure 1).

\section{Patient / Study Characteristics}

All six studies reported the conservative management strategy with five of six studies (83\%) using intravenous fluids, all six studies (100\%) adopting bowel rest and five of six studies (83\%) using percutaneous drainage as an adjunct and intravenous antibiotics. The specific antibiotic regimen include; intravenous amoxicillin/clavulanic, piperacillin-tazobactam and cefuroxime/metronidazole. Majority of patients $(n=321$; $67 \%)$ had pericolic free air, and distant free air was present in 180 patients (38\%) (Table 1). 


\section{Treatment Outcomes}

Of 479 patients, 412 patients (86\%) were successfully managed non-operatively. Sixty-five patients (13.6\%) failed non-operative treatment and underwent operative surgical management, and two patients died (0.4\%). Of the two patients who died, the first was an elderly patient who had an intra-abdominal abscess that was deemed unsuitable for percutaneous drainage and due to age, decided against emergency surgery. The second patient failed to improve after percutaneous drainage and proceeded for a Hartmann procedure but died due to severe sepsis from peritonitis. The operative procedure performed was recorded in 45 of 65 patients and include Hartmann operation $(n=23,51 \%)$, resection with anastomosis with or without stoma $(n=12,27 \%)$, laparoscopic lavage $(n=8,18 \%)$ and surgical drainage $(n=2,4 \%)$. Specific to the type of extraluminal air, there were data available on 186 patients with pericolic extraluminal air and 180 patients with distant extraluminal air who were managed non-operatively. The success rate for pericolic and distant extraluminal air was $92.4 \%$ (172 of 186 patients) and $71.4 \%$ (65 of 91 patients) respectively (Table 2).

From Table 3, failure of non-operative management was not associated with elderly age (5 of 6 studies; 83\%), male gender (4 of 6 studies; $67 \%$ ), and fever (5 of 6 studies; 83\%). There were weak associations suggesting that a higher volume of free air (3 of 6 studies; 50\%), distant free air (3 of 6 studies; 50\%) and presence of abscess (3 of 6 studies; 50\%) being associated with failure of non-operative management. 


\section{DISCUSSION}

Diverticulitis with perforation is a distinct disease entity affecting a subset of patients with diverticulitis. Clinical assessment and correlation of imaging findings form the cornerstone of management. Increasingly, the surgical management of diverticulitis has shifted towards a non-operative approach of bowel rest and broad-spectrum intravenous antibiotics in conjunction with interventional procedures to drain abscesses where necessary. In the emergency setting, surgery is indicated in patients with sepsis and peritonitis from complicated diverticulitis or in those who have failed medical therapy, percutaneous drainage or both [15]. In the elective setting, there has been a change to the long-held dogma of prophylactic colectomies to prevent the recurrence of acute diverticulitis and complicated diverticulitis [16]. The American Society of Colon and Rectal Surgeons (ASCRS) has recommended against elective colectomies as the data has not shown to decrease subsequent admissions nor rates of emergency surgery for diverticulitis [17, 18]. Elective colectomies following recovery from acute diverticulitis should be individualized to each patient taking into account the severity of symptoms from diverticular disease balanced against the risk of the operation.

From our review, we identified that free air can occur in a pericolic or distant location. This can be associated with or without abscesses. In addition, it is important to evaluate the volume of free air [19]. This information gathered from computed tomography imaging when evaluated in conjunction with clinical observation parameters will indicate the overall severity of the diverticular perforation. Based on experience with operating on patients with perforated diverticulitis, a large volume 
free gas is often associated with a significant perforation. Distant extraluminal freegas would indicate a failure to immediately seal the perforation or a significant perforation as opposed to patients with only pericolic free gas are likely to have sealed the perforation and will respond to conservative management. Predictive factors of treatment failure from conservative management identified through our review include a high volume of free air (described as $>2 \mathrm{~cm}$ on cross sectional CT imaging), distant free air and the presence of an abscess. Taken together, these clinical and imaging findings identify patients at high risk for failure of conservative management and indicate a persistent perforation. Persistent perforation is a concept defined as a histologically proven perforation present within the surgically resected specimen. O'Leary et al. observed that in patients who underwent operative management for acute diverticulitis with peritonitis, perforation identified histologically was associated with increased morbidity, length of stay, physiological score and operative severity score [20]. Persistent perforation could explain the high rates of treatment failure after laparoscopic lavage for acute perforated diverticulitis where persistent and recurrent intra-abdominal sepsis occur due to peritonitis and ongoing abscess formation translating into higher reoperation rates and increase mortality [21].

Therefore, every effort should be made firstly to distinguish patients with acute perforated diverticulitis who have generalised peritonitis requiring an emergency operation versus those who do not have generalised peritonitis, which may be managed conservatively. If an emergency operation is required upfront or following failure of conservative management, the surgical options include a Hartmann's 
operation with formation of a colostomy, a sigmoid resection with anastomosis with or without defunctioning ileostomy [22]. Secondly, in the subgroup that are suitable to trial conservative management, it must be recognised that this approach is likely successful in approximately $85 \%$ of patients as observed in our review. However, the described clinical behaviour of a patient with a persistent perforation that can occur in up to $15 \%$ of patients who are conservatively managed needs to be recognised early to reduce the morbidity and mortality of this treatment strategy.

This review is limited by the small number of studies available in the literature investigating this relatively commonly encountered clinical problem observed in a subgroup of patients with acute diverticulitis. Further, the studies that were identified and included this semi-quantitative and narrative review are one-arm studies evaluating the role of non-operative treatments for perforated diverticulitis without a similar comparison group of that undergoing upfront resection. As a result, this precludes the performance of a meta-analysis.

The concept of persistent perforation needs increased awareness and is the likely explanation for treatment failure of the conservative management strategy. In summary, conservative management is safe and successful in patients with acute perforated diverticulitis without generalised peritonitis and can be advocated as the first line approach with intravenous antibiotics and interventional radiological adjuncts when required. Early recognition of patients who demonstrate clinical signs of persistent perforation is important to ensure the success of this strategy. 
TABLE 1. Summary of Study Numbers and Management Strategies

\begin{tabular}{|c|c|c|c|c|c|c|c|c|c|}
\hline & & & & \multicolumn{4}{|c|}{ Non-Operative Approach } & \multirow[b]{2}{*}{$\begin{array}{c}\text { Pericolic } \\
\text { Extraluminal } \\
\text { Air (n) } \\
\end{array}$} & \multirow[b]{2}{*}{$\begin{array}{c}\text { Distant } \\
\text { Extraluminal } \\
\text { Air }(\mathrm{n}) \\
\end{array}$} \\
\hline nor, Year & Institution & Period & $\begin{array}{l}\text { Non- } \\
\text { Operatively } \\
\text { (n) }\end{array}$ & $\begin{array}{l}\text { IV } \\
\text { Fluids }\end{array}$ & IV Antibiotics & $\begin{array}{l}\text { Bowel } \\
\text { Rest }\end{array}$ & $\begin{array}{l}\text { Percutaneous } \\
\text { Drainage }\end{array}$ & & \\
\hline Iuvs-Garcia, 2017 [9] & $\begin{array}{c}\text { University } \\
\text { Regional } \\
\text { Hospital, Spain }\end{array}$ & $2010-2015$ & 64 & Yes & NR & Yes & Yes & 51 & 13 \\
\hline Costi, 2012 [10] & $\begin{array}{l}\text { Assistance } \\
\text { Publique } \\
\text { Hospitaux de } \\
\text { Paris, France } \\
\end{array}$ & $2001-2010$ & 39 & Yes & $\begin{array}{l}\text { Amoxicillin / } \\
\text { Clavulanic } \\
\text { Acid }\end{array}$ & Yes & Yes & 31 & 8 \\
\hline Thr isson, 2018 [11] & $\begin{array}{c}\text { Vastmanland's } \\
\text { Hospital } \\
\text { Vasteras, } \\
\text { Sweden } \\
\end{array}$ & $2010-2014$ & 107 & Yes & $\begin{array}{l}\text { Piperacillin / } \\
\text { Tazobactam }\end{array}$ & Yes & Yes & 104 & 32 \\
\hline As, 2017 [12] & $\begin{array}{c}\text { Multi- } \\
\text { Institutional }\end{array}$ & $2009-2015$ & 91 & No & $\begin{array}{l}\text { Amoxicillin / } \\
\text { Clavulanic } \\
\text { Acid or } \\
\text { Ciprofloxacin / } \\
\text { Metronidazole } \\
\end{array}$ & Yes & No & 34 & 57 \\
\hline Sallinen, 2014 [13] & $\begin{array}{c}\text { Helsinki } \\
\text { University } \\
\text { Central Hospital, } \\
\text { Finland } \\
\end{array}$ & $2006-2010$ & 132 & Yes & $\begin{array}{l}\text { Cefuroxime } \\
\text { and } \\
\text { Metronidazole } \\
\end{array}$ & Yes & Yes & 82 & 43 \\
\hline Dharmarajan, 2011 [14] & $\begin{array}{l}\text { Barnes-Jewish } \\
\text { Hospital, United }\end{array}$ & $1995-2008$ & 46 & & & & & 19 & 27 \\
\hline
\end{tabular}

This article is protected by copyright. All rights reserved. 


\begin{tabular}{|c|c|c|c|c|c|c|c|c|}
\hline & States & & Yes & NR & Yes & Yes & & \\
\hline D & & 479 & & & & & 321 & 180 \\
\hline
\end{tabular}


TABLE 2. Outcomes of Conservative Management

\begin{tabular}{|c|c|c|c|c|c|c|c|c|}
\hline \multirow[b]{2}{*}{ Author, Year } & \multirow[b]{2}{*}{$\begin{array}{c}\text { Successful } \\
\text { Non-Operative } \\
\text { Management } \\
(\%, n) \\
\end{array}$} & \multicolumn{5}{|c|}{ Failed Management Treatment } & \multirow[b]{2}{*}{$\begin{array}{c}\text { Pericolic } \\
\text { Successful } \\
\text { Non-Operative } \\
\text { Treatment (\%n) }\end{array}$} & \multirow[b]{2}{*}{$\begin{array}{c}\text { Distant } \\
\text { Successful } \\
\text { Non-Operative } \\
\text { Treatment }(\%, n)\end{array}$} \\
\hline & & Total (n) & $\begin{array}{c}\text { Hartmann } \\
\text { Procedure } \\
(\%, n)\end{array}$ & $\begin{array}{c}\text { Resection +l- } \\
\text { Primary } \\
\text { Anastomosis } \\
(\%, n)\end{array}$ & $\begin{array}{c}\text { Mortality } \\
(\%, n)\end{array}$ & $\begin{array}{l}\text { Other } \\
(\%, n)\end{array}$ & & \\
\hline Titos-Garcia, 2017 [9] & $84 \%(54)$ & 10 & $30 \%(3)$ & $50 \%(5)$ & $10 \%(1)$ & $10 \%(1)$ & $90 \%(46)$ & $62 \%(8)$ \\
\hline usti, $2012[10]$ & $92 \%(36)$ & 3 & $0 \%(0)$ & $33 \%(1)$ & $0 \%(0)$ & $67 \%(2)$ & $90 \%(28)$ & $100 \%(8)$ \\
\hline T' orisson, 2018 [11] & $93 \%(101)$ & 6 & $50 \%(3)$ & $50 \%(3)$ & $0 \%(0)$ & $0 \%(0)$ & NR & NR \\
\hline Colas, 2017 [12] & $77 \%(70)$ & 21 & $48 \%(10)$ & $14 \%(3)$ & $5 \%(1)$ & $33 \%(7)$ & NR & NR \\
\hline Sallinen, 2014 [13] & $85 \%(112)$ & NR & NR & NR & NR & NR & $99 \%(81)$ & $56 \%(24)$ \\
\hline nharmarajan, 2011 [14] & $85 \%(39)$ & 7 & $100 \%(7)$ & $0 \%(0)$ & $0 \%(0)$ & $0 \%(0)$ & $90 \%(17)$ & $93 \%(25)$ \\
\hline Trtal & 412 & 47 & & & & & & \\
\hline Median & $85 \%$ & & $48 \%$ & $33 \%$ & $0 \%$ & $10 \%$ & $90 \%$ & $78 \%$ \\
\hline$\Gamma$ nge & $77-93 \%$ & & $0-100 \%$ & $0-50 \%$ & $0-10 \%$ & $0-67 \%$ & $90-99 \%$ & $56-100 \%$ \\
\hline
\end{tabular}


TABLE 3. Associations of Clinical Factors with Outcomes

\begin{tabular}{|c|c|c|}
\hline & Significant (Positive Association) & Nonsignificant (No Association) \\
\hline Older Age & & $\begin{array}{l}\text { Thorinsson, Costi, Sallinien, Colas, } \\
\text { Titos-Garcia }\end{array}$ \\
\hline Iale & & $\begin{array}{l}\text { Thorinsson, Sallinien, Colas, Titos- } \\
\text { Garcia }\end{array}$ \\
\hline mmunosuppression & & Thorisson, Colas, Sallinien \\
\hline Tachycardia & Colas & \\
\hline lospital length of stay & Colas & \\
\hline WBC count & Costi & Colas, Sallinien, Titos-Garcia \\
\hline 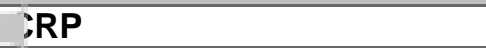 & Costi, Colas & Thorisson, Sallinien, Titos-Garcia \\
\hline Fever & & $\begin{array}{l}\text { Sallinien, Titos-Garcia, Costi, } \\
\text { Thorisson, Colas }\end{array}$ \\
\hline Previous episiodes & Sallinien & Costi, Colas, Titos-Garcia \\
\hline Drevious antibiotic therapy & Costi & Titos-Garcia \\
\hline Mean duration of symptoms & Costi & \\
\hline ISA & Titos-Garcia & Colas, Costi \\
\hline Peritonism & & Colas, Sallinien, Costi \\
\hline Volume of free air & Sallinien, Colas, Titos-Garcia & Costi, Thorinsson \\
\hline Pericolic air & & Sallinien, Titos-Garcia, Colas \\
\hline Distant free air & Sallinein, Titos-Garcia, Colas & Costi \\
\hline Dresence of free fluid & Costi, Colas & Thorinsson \\
\hline Pelvic free fluid & Sallinen & Colas \\
\hline Abscess & Titos-Garcia, Sallinien, Thorinsson & \\
\hline
\end{tabular}




\section{REFERENCES}

1. Weizman AV, Nguyen GC. Diverticular disease: epidemiology and management. Can J Gastroenterol 2011; 25: 385-389.

2. Schoetz DJ. Diverticular disease of the colon: a century-old problem. Dis Colon Rectum 1999; 42: 703-709.

3. Van Arendonk KJ, Tymitz KM, Gearhart SL et al. Outcomes and costs of elective surgery for diverticular disease: a comparison with other diseases requiring colectomy. . JAMA Surg 2013; 148: 316-231.

4. $\quad$ van Dijk ST, Daniels L, Ünlü Ç et al. Long-Term Effects of Omitting Antibiotics in Uncomplicated Acute Diverticulitis. American Journal of Gastroenterology 2018; 113: 1045-1052.

5. Huston JM, Zuckerbraun BS, Moore LJ et al. Antibiotics versus No Antibiotics for the Treatment of Acute Uncomplicated Diverticulitis: Review of the Evidence and Future Directions. Surg Infect (Larchmt) 2018; 19: 648-654. 6. Hinchey EJ, Schaal, P.G. and Richard, G.K. . Treatment of perforated diverticular disease of the colon. Advances in Surgery 1978; 12: 85-109.

7. Francis NK, Sylla P, Abou-Khalil M et al. EAES and SAGES 2018 consensus conference on acute diverticulitis management: evidence-based recommendations for clinical practice. Surg Endosc 2019; 33: 2726-2741. 8. Bridoux V, Regimbeau JM, Ouaissi M et al. Hartmann's Procedure or Primary Anastomosis for Generalized Peritonitis due to Perforated Diverticulitis: A Prospective Multicenter Randomized Trial (DIVERTI). J Am Coll Surg 2017; 225: 798-805.

9. Titos-García A, Aranda-Narváez JM, Romacho-López L et al. Nonoperative management of perforated acute diverticulitis with extraluminal air: results and risk factors of failure. Int J Colorectal Dis 2017; 32: 1503-1507.

10. Costi R, Cauchy F, Le Bian A et al. Challenging a classic myth: pneumoperitoneum associated with acute diverticulitis is not an indication for open or laparoscopic emergency surgery in hemodynamically stable patients. A 10-year experience with a nonoperative treatment. Surg Endosc 2012; 26: 20612071.

11. Thorisson A, Nikberg M, Andreasson $\mathrm{K}$ et al. Non-operative management of perforated diverticulitis with extraluminal or free air - a retrospective single center cohort study. Scand J Gastroenterol 2018; 53: 1298-1303.

12. Colas PA, Duchalais E, Duplay Q et al. Failure of Conservative Treatment of Acute Diverticulitis with Extradigestive Air. World J Surg 2017; 41: 1890-1895.

13. Sallinen VJ, Mentula PJ, Leppäniemi AK. Nonoperative management of perforated diverticulitis with extraluminal air is safe and effective in selected patients. Dis Colon Rectum 2014; 57: 875-881.

14. Dharmarajan S, Hunt SR, Birnbaum EH et al. The efficacy of nonoperative management of acute complicated diverticulitis. Dis Colon Rectum 2011; 54: 663-671. 
15. Acuna SA, Wood T, Chesney TR et al. Operative Strategies for Perforated Diverticulitis: A Systematic Review and Meta-analysis. Dis Colon Rectum 2018; 61: 1442-1453.

16. Simianu VV, Fichera A, Bastawrous AL et al. Number of Diverticulitis Episodes Before Resection and Factors Associated With Earlier Interventions. JAMA Surg 2016; 151: 604-610.

17. Feingold D, Steele SR, Lee $S$ et al. Practice parameters for the treatment of sigmoid diverticulitis. Dis Colon Rectum 2014; 57: 284-294.

18. Simianu VV, Strate LL, Billingham RP et al. The Impact of Elective Colon Resection on Rates of Emergency Surgery for Diverticulitis. Ann Surg 2016; 263 : 123-129.

19. Kaiser AM, Jiang JK, Lake JP. The management of complicated diverticulitis and the role of computed tomography. Am J Gastroenterol 2005; 100: 910-917.

20. O'Leary DP, Myers E, O'Brien 0 et al. Persistent perforation in nonfaeculant diverticular peritonitis--incidence and clinical significance. J Gastrointest Surg 2013; 17: 369-373.

21. Penna M, Markar SR, Mackenzie H et al. Laparoscopic Lavage Versus Primary Resection for Acute Perforated Diverticulitis: Review and Meta-analysis. Ann Surg 2018; 267: 252-258.

22. Biondo S. The diminishing role of surgery for acute diverticulitis. Br J Surg 2019; 106: 308-309. 
TABLE LEGEND

TABLE 1. Summary of Study Numbers and Management Strategies

TABLE 2. Outcomes of Conservative Management

TABLE 3. Associations of Clinical Factors with Outcomes

FIGURE LEGEND

FIGURE 1. Literature search strategy 

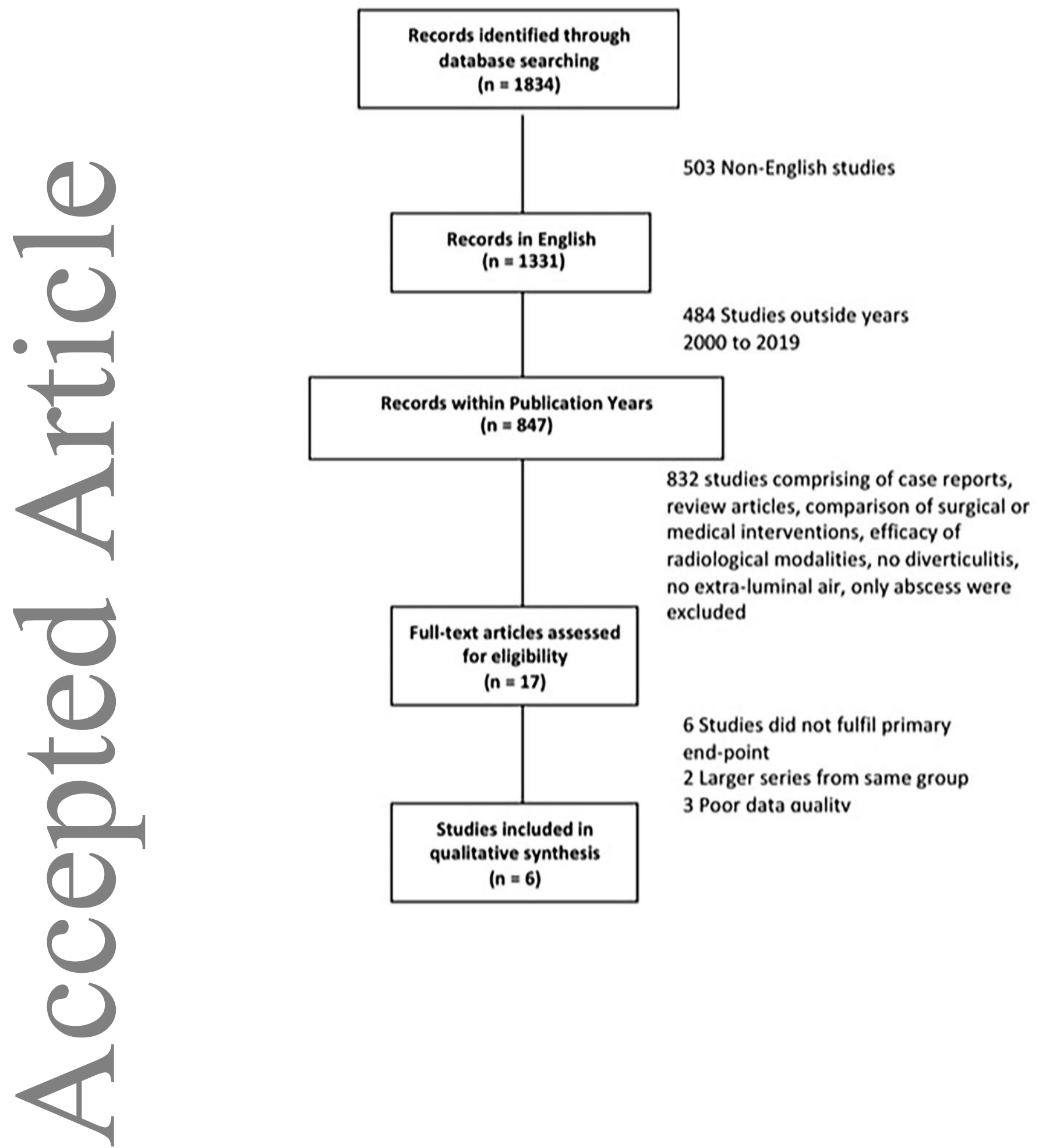